\title{
Does mean platelet volume and neutrophil to lymphocyte ratio increase in primary hyperparathyroidism arising from a single adenoma
}

\author{
Isilay Kalan Sari', ${ }^{1}$ Serkan Ceylan ${ }^{2}$ \\ ${ }^{1}$ Department of Endocrinology and Metabolic Disorders, University of Health Sciences, Antalya Training and Research \\ Hospital, Antalya, Turkey \\ ${ }^{2}$ Department of General Surgery, University of Health Sciences, Antalya Training and Research Hospital, Antalya, \\ Turkey
}

\section{ABSTRACT}

\begin{abstract}
Aim: Primary hyperparathyroidism (PHP) is commonly caused by adenomas. Studies have shown mild inflammation in PHP and elevated levels of some inflammatory markers to support this. In addition, excess parathyroid hormone (PTH) and calcium (Ca) cause atherosclerosis by disrupting endothelial function. Mean platelet volume (MPV) describes the size and indirect activity of platelets and its value is expected to increase with inflammation and associated atherosclerosis. Neutrophil to lymphocyte ratio (NLR) is another parameter associated with inflammatory response. This study was performed to investigate the MPV and NLR levels in PHP developing from a single parathyroid adenoma.
\end{abstract}

Method: Patient records from 2016-2021 were retrospectively scanned from the computer system and 40 patients with PHP developing from a single parathyroid adenoma were selected based on exclusion criteria. The values of PTH, Ca, 25-Hydroxyvitamin D, phosphorus, MPV and number of blood cells were recorded. NLR was calculated. The results were compared with the results of 36 healthy controls.

Results: MPV ( $8.7 \pm 0.6 \mathrm{fl}$ and $7.6 \pm 0.6 \mathrm{fl}$, respectively; $p=0.001)$ and NLR $(2.6 \pm 1.7$ and $1.7 \pm 0.8$, respectively; $p=0.000)$ were higher in the PHP group compared to the control group. Ca and PTH correlated positively with MPV ( $p=0.003$ and $p=0.000$, respectively) and NLR ( $p=0.011$ and $p=0.023$, respectively).

Conclusion: MPV and NLR were found to be higher in patients with PHP developing from a single adenoma than in healthy individuals.

Key words: Mean platelet volume, neutrophil to lymphocyte ratio, primary hyperparathyroidism, parathyroid adenoma, calcium.

$\triangle$ Dr. Isilay Kalan Sari

Department of Endocrinology and Metabolic Disorders, University of Health Sciences, Antalya Training and Research Hospital, Antalya, Turkey

E-mail: isilaykalan@gmail.com

Received: 2021-05-13 / Revisions: 2021-11-04

Accepted: 2021-12-14 / Published online: 2022-01-01

\section{Introduction}

Parathyroid adenomas are the most common cause of primary hyperparathyroidism (PHP) and are increasingly encountered in clinical practice with increased ultrasound experience and widespread measurement of calcium $(\mathrm{Ca})$, 25-hydroxyvitamin D (25OHD), and parathyroid hormone (PTH). Early diagnosis also allows patients to be caught mostly in the asymptomatic phase. Therefore, clinical studies have focused on investigating whether high PTH and Ca levels cause other pathologies in this group of patients without typical bone and 
renal involvement [1-7]. In these studies, the PTH-1 receptor has also been observed outside of bone and kidney which are typical sites of PTH action [3]. Apart from these two regions, the PTH-1 receptor was most frequently detected in the heart and vascular network, which is why the cardiac effects of PTH have begun to be studied [3-7]. These studies showed that PTH exerts chronotropic and inotropic effects on the heart and is a causative factor for left ventricular hypertrophy and hypertension [4,5]. Studies have shown mild inflammation in PHP and increased levels of some inflammatory markers (interleukin-6, highsensitivity C-reactive protein) supporting this [6,7]. Moreover, excess PTH and Ca cause atherosclerosis by disrupting endothelial function [8,9]. Platelets are involved in the development of inflammation and play a special role in hemostasis and thrombosis [10]. Platelets express and secrete CD40 ligand, which stimulates inflammation in the endothelium, and platelet cytoplasmic granules contain numerous inflammatory products, including leukotrienes, prostaglandins, plateletactivating factor, beta-thromboglobulin, and interleukin-1 [11-13]. MPV describes the size and indirectly the activity of platelets [14]. Therefore, its value is expected to increase in inflammation and associated atherosclerosis, in which platelet activity increases [15-16]. Studies have also supported this idea, and MPV has been found to be increased in chronic inflammatory diseases such as ankylosing spondylitis, rheumatoid arthritis, and inflammatory bowel disease, as well as in acute inflammatory processes such as unstable angina and myocardial infarction [17-20]. MPV has also been associated with infections such as coronavirus 2019 (Covid-19), obesity, diabetes mellitus, frailty, and coronary artery disease [21-24]. The neutrophil to lymphocyte ratio
(NLR) is obtained by dividing the neutrophil count by lymphocyte count in the complete blood count and is one of the markers of the inflammatory response [25]. The positive association between high-sensitivity C-reactive protein and systemic inflammation also supports this finding [25]. NLR has been found to help predict prognosis in some diseases, indicating poor prognosis in cardiovascular disease, solid tumors, and infections [26-28]. This study was conducted to investigate the level of MPV and NLR in PHP developing from a single parathyroid adenoma.

\section{Materials and methods}

After obtaining ethics committee approval (date: 10/06/2021; decision number: 8/21), the data of subjects who visited the endocrinology and/or general surgery departments of Antalya Training and Research Hospital between January 2016 and April 2021 were reviewed. The exclusion criteria were as follows: PHP due to hyperplasia of the parathyroid glands, PHP patients with multiple adenomas, cases with surgical pathologies of parathyroid cancer, younger than 18 and older than 70 years, with cardiovascular or cerebrovascular diseases, taking medications that affect platelet function (e.g., acetylsalicylates, heparin, antiepileptic drugs, etc.), and with infections or inflammatory diseases. Patient records were retrospectively scanned from the computer system, and 40 PHP patients with solitary parathyroid adenoma who met the exclusion criteria were identified and included in the study. The study population was formed by selecting 36 controls of similar age and gender with normal serum PTH and Ca levels. In all patients, PHP diagnosis had been based on at least two separate measurements of $\mathrm{Ca}$, phosphorus (P), albumin, and $\mathrm{PTH}$, and at least one measurement of 25OHD and 24-hour urine 
$\mathrm{Ca}$ and creatinine. The diagnosis of adenoma was confirmed by the presence of adenoma on Technetium (99mTc) sestamibi scintigraphy in addition to the ultrasound image, and by PTH washout from the lesion on ultrasound if the scintigraphy was negative. $\mathrm{Ca}, \mathrm{P}$, albumin, and other biochemical tests results were obtained by the traditional spectrophotometric method using commercial kits from Beckman Coulter with a Beckman Coulter AU5800 autoanalyzer (Beckman Coulter Inc., CA, USA), and the result of whole blood parameters (hemogram) were obtained with a Beckman Coulter LH780 hematology autoanalyzer. PTH, 25OHD and other necessary hormone tests were performed using the chemiluminescence method on a Beckman Coulter DxI800 instrument (Beckman Coulter Inc.). The reference ranges in our hospital were $8.8-10.6 \mathrm{mg} / \mathrm{dl}$ for $\mathrm{Ca}, 2.5$ $4.5 \mathrm{mg} / \mathrm{dl}$ for P, 12-88 ng/l for PTH, and 3.6-12 fl for MPV between the study dates. Serum levels of $\mathrm{Ca}, \mathrm{P}$, albumin, PTH, 25OHD and hemogram of total population were recorded. If the patient's albumin is low, it was analyzed by calculating the corrected $\mathrm{Ca}$ for albumin [Corrected $\mathrm{Ca}(\mathrm{mg} / \mathrm{dl})=$ measured $\mathrm{Ca}(\mathrm{mg} / \mathrm{dl})$ +0.8 (4-patient albumin). 25OHD level below 20ng/ml was considered as insufficient. We statistically compared the MPV and NLR values of patients and controls and examined the correlation between these parameters and PTH, 25OHD and Ca.

\section{Statistical analysis}

All results were given as numbers and percentages for categorical parameters and means and standard deviations for continuous variables. Analyzes were obtained in SPSS 20.0 program. Whether the distribution of the data was normal or not was determined by performing the Shapiro-Wilk test. The comparison of the means of the two groups that met the parametric analysis conditions was made with the Student's T-test and the Mann Whitney U test was used when comparing the means of nonparametric variables. Spearman correlation test was used to identify possible relationships among the parameters. It was considered significant when the $p$ value was below 0.05 .

\section{Results}

40 PHP patients with a mean age of $50.6 \pm 7.3$ years and 36 controls with a mean age of $49.8 \pm 8.1$ years were studied. $29(72.5 \%)$ of the PHP patients were female, while 26 (72.2\%) of the control subjects were female. Mean PTH level was significantly higher in patients than control subjects $(214.9 \pm 112.6 \quad \mathrm{ng} / \mathrm{l}$ and $49.0 \pm 6.3 \mathrm{ng} / \mathrm{l}$, respectively; $p=0.001$ ). The mean 25OHD level in the PHP group indicated insufficiency, while the 25OHD level in the control group was adequate $(18.1 \pm 7.6 \mu \mathrm{g} / \mathrm{l}$ and $26.6 \pm 4.0 \mu \mathrm{g} / \mathrm{l}$, respectively; $p=0.024)$. The mean Ca level was $11.6 \pm 0.9 \mathrm{mg} / \mathrm{dl}$ in patients, $9.2 \pm 1.0 \mathrm{mg} / \mathrm{dl}$ in controls $(p=0.012)$. $\mathrm{P}$ level was lower in patients than in controls as expected $(2.4 \pm 0.02 \mathrm{mg} / \mathrm{dl}$ and $3.5 \pm 0.4 \mathrm{mg} / \mathrm{dl}$, respectively; $p=0.002$ ). Red blood cell count and hemoglobin content were similar in the 2 groups. While platelet count did not change between patients and controls, MPV was significantly higher in patients compared to controls $(8.7 \pm 0.6 \mathrm{fl}$, and $7.6 \pm 0.6 \mathrm{fl}$, respectively; $\quad p=0.001$ ), supporting our hypothesis. The white blood cell count did not differ between the groups, but the neutrophil count was significantly increased in the PHP patients $(p=0.000)$. In addition, NLR was significantly higher in the PHP group than in the control group $(2.6 \pm 1.7$ and $1.7 \pm 0.8$, respectively; $p=0.000$ ). The comparison of study parameters between patients and controls is shown in Table 1. We found a significant correlation between PTH and MPV (r=0.476, 
Table 1. Table 1. Comparison of the parameters between patients and controls.

\begin{tabular}{|c|c|c|c|}
\hline Parameters & PHP group & Control group & $p$ \\
\hline Number (n) & 40 & 36 & \\
\hline $\begin{array}{r}\text { Male/Female (n) } \\
(\%)\end{array}$ & $\begin{array}{c}11 / 29 \\
(27.5 / 72.5)\end{array}$ & $\begin{array}{c}10 / 26 \\
(27.8 / 72.2)\end{array}$ & 0.986 \\
\hline Age (yrs.) & $50.6 \pm 7.3$ & $49.8 \pm 8.1$ & 0.812 \\
\hline PTH (ng/l) & $214.9 \pm 112.6$ & $49.0 \pm 6.3$ & $0.001 *$ \\
\hline $25 \mathrm{OHD}(\mu \mathrm{g} / \mathrm{l})$ & $18.1 \pm 7.6$ & $26.6 \pm 4.0$ & $0.024 *$ \\
\hline Calcium (mg/dl) & $11.6 \pm 0.9$ & $9.2 \pm 1.0$ & $0.012 *$ \\
\hline Phosphous (mg/dl) & $2.4 \pm 0.02$ & $3.5 \pm 0.4$ & $0.002 *$ \\
\hline MPV (fl) & $8.7 \pm 0.6$ & $7.6 \pm 0.6$ & $0.001 *$ \\
\hline Neutrophil $\left(10^{3} / \mu \mathrm{l}\right)$ & $5.7 \pm 1.4$ & $4.2 \pm 1.9$ & $0.000 *$ \\
\hline Lymphocyte $\left(10^{3} / \mu \mathrm{l}\right)$ & $2.2 \pm 1.0$ & $2.5 \pm 0.6$ & 0.267 \\
\hline NLR & $2.6 \pm 1.7$ & $1.7 \pm 0.8$ & $0.000 *$ \\
\hline
\end{tabular}

${ }^{*} p<0.05$ is statistically significant PTH, parathyroid hormone; PHP, primary hyperparathyroidism; MPV, mean platelet volume; NLR, neutrophil to lymphocyte ratio; $25 O H D, 25$-hydroxyvitamin D.

$p=0.000)$ positive, between $\mathrm{Ca}$ and MPV $(\mathrm{r}=0.292, \mathrm{p}=0.003)$ positive and between MPV and 25OHD ( $\mathrm{r}=-0.367, p=0.024)$ negative. In addition, NLR showed significant positive correlation with serum $\mathrm{Ca}(\mathrm{r}=0.214, p=0.011)$ and PTH ( $\mathrm{r}=0.347, p=0.023)$ and negative correlation with 25OHD which was not

Tablo 2. The result of correlation analysis.

\begin{tabular}{|l|l|l|}
\hline Parameters & MPV & NLR \\
\hline PTH & r:0.476 & r:0.347 \\
& $\boldsymbol{p}: 0.000 *$ & $\boldsymbol{p}: \mathbf{0 . 0 2 3} *$ \\
\hline \multirow{2}{*}{ Calcium } & r:0.292 & r: 0.214 \\
& $\mathbf{p : 0 . 0 0 3 *}$ & $\mathbf{p : ~} \mathbf{0 . 0 1 1} *$ \\
\hline \multirow{2}{*}{ 25OHD } & r:-0.367 & r: -0.072 \\
& $p: 0.024 *$ & $p: 0.131$ \\
\hline
\end{tabular}

PTH, parathyroid hormone; MPV, mean platelet volume; NLR, neutrophil to lymphocyte ratio; 25OHD, 25-hydroxyvitamin $D . \quad *_{p}<0.05$ is statistically significant, spearman correlation tests. statistically significant $(\mathrm{r}=-0.072, p=0.131)$. The correlation results are shown in Table 2 .

\section{Discussion}

In our study, we found that MPV, which was expected to increase in platelet activation, and NLR, which is positively correlated with inflammatory parameters were significantly higher in PHP patients than in healthy controls. MPV was found to be increased in chronic inflammatory diseases, many cancer types including thyroid papillary carcinoma as well as in cardiovascular diseases such as coronary artery disease and myocardial infarction (MI) [16-18,29]. Butterworth RJ et al., showed that MPV is also increased in ischemic stroke and that MPV on admission is significantly higher in patients who died or became dependent at 3 months after stroke [30]. In another study, an increase in MPV was observed after MI, 
suggesting that it may be a predictor of death or other ischemic events after MI [18]. The study, which compared thyroid cancer patients who underwent surgery with healthy controls and operated thyroid patients with benign goiter pathology, concluded that the MPV increase in thyroid papillary cancer was significant compared to other groups (29). Another study by Kuzu F et al., on thyroid nodules found that MPV and NLR were high in malignant nodules (31). Also, in studies on MPV in thyroid patients, it was observed that MPV increased in autoimmune thyroid diseases irrespective of TSH level (32). An increase in MPV was also observed in Graves' orbitopathy, which is also an autoimmune inflammatory process (33). In patients with PHP, inflammation, endothelial dysfunction, and the atherosclerosis cascade are activated by pathways whose mechanisms are not clearly understood. The consequence of this process is a poor prognosis and an increased risk of death from cardiovascular disease [3-9]. To elucidate this etiopathogenesis, platelet functions have been brought to the forefront and it has been suggested that changes in coagulation parameters, susceptibility to thrombosis and increased platelet activation may occur in PHP $[34,35]$. It is known that the number of studies investigating platelet function and activation in PHP is quite limited. In these studies, some factors of the coagulation cascade, coagulation and adhesion molecules were measured. One study found that the levels of the factor VII and D-dimer were higher in PHP patients than in control subjects [34], while in another study, P-selectin levels and aggregation parameters did not differ between PHP and control groups [35]. In studies that investigated MPV in PHP, the results were consistent with ours [36-38]. Y1lmaz et al, on the other hand, found that MPV values decreased significantly in the 6th month after adenoma surgery [37]. Baradaran et al., studied MPV levels in secondary hyperparathyroidism in dialysis patients and found that there was a direct correlation between MPV and PTH in this group of patients, and observed that platelet count decreased with increasing PTH [38]. Some studies hypothesized that increased $\mathrm{Ca}$ levels, rather than PTH, affected platelets in $\mathrm{PHP}$, leading to an increase in platelet $\mathrm{Ca}$ levels by altering platelet shape and activation $[39,40]$. It has also been suggested that increased inflammation and oxidative stress may cause platelet activation in PHP [41,42]. Similar to our results, Cure et al. [42] and Arpaci D et al., [36] found a negative correlation between MPV and 25OHD levels. In agreement with previous reports [43,44], females in this study were more likely to have a PHP than males. Another finding of our study is that NLR is higher in subjects with PHP than in healthy subjects. NLR, which can be derived from leukocyte count, increases in systemic inflammation [45]. Some data suggest that NLR may be related to cardiovascular disease prognosis [26,45]. In a few studies investigating the influence of PHP on NLR, a positive correlation between PTH and NLR was documented [46,47]. In this study, Zeren S et al., found that NLR increased with increasing parathyroid adenoma size [47]. In another study that focused attention on NLR in patients who developed primary or secondary PTH elevation, it was highlighted that due to the positive correlation between PTH and $\mathrm{Ca}$ and NLR, elevated PTH would indicate a proinflammatory state [48]. Our study has some limitations. The study population was small, the study was retrospective, and we did not measure other atherosclerotic or inflammatory markers and platelet activation parameters.

\section{Conclusion}

The significance of this study is that it 
demonstrates increased platelet activation and inflammatory propensity in PHP and paves the way for new studies to assess inflammatory markers and adhesion and aggregation molecules in relation to platelet activity. In our study, we found that MPV, which is an indicator of platelet activation, and NLR, which correlates with inflammatory parameters, increase in PHP due to a single parathyroid adenoma, but new studies on the clinical significance of these findings are needed.

There is no conflict of interest.

Funding: The author(s) received no financial support for the research, authorship, and/or publication of this article.

Conflict of Interest: The authors declare that they have no conflict of interest.

Ethical statement: The study was conducted with the approval of Local Ethical Committee in accordance with the Helsinki Declaration After obtaining ethics committee approval (date: 10/06/2021; decision number: 8/21).

\section{Open Access Statement}

This is an open access journal which means that all content is freely available without charge to the user or his/her institution under the terms of the Creative Commons Attribution NonCommercial License (https://creativecommons.org/licenses/by/4.0/). Users are allowed to read, download, copy, distribute, print, search, or link to the full texts of the articles, without asking prior permission from the publisher or the author.

Copyright (c) 2021: Author (s).

\section{References}

[1]Marx SJ. Hyperparathyroid and hypoparathyroid disorders. N Engl J Med. 2000;343(25):1863-75.

[2]Solomon BL, Schaaf M, Smallridge RC. Psychologic symptoms before and after parathyroid surgery. Am J Med. 1994;96(2):101-6.

[3]Chorev M. Parathyroid hormone 1 receptor: insights into structure and function. Recept Channels. 2002;8(3-4):219-42.

[4]Taylor EN, Curhan GC, Forman JP. Parathyroid hormone and the risk of incident hypertension. J Hypertens. 2008;26(7):1390-94.

[5]van Ballegooijen AJ, Visser M, Kestenbaum $\mathrm{B}$, et al. Relation of vitamin $\mathrm{D}$ and parathyroid hormone to cardiac biomarkers and to left ventricular mass (from the Cardiovascular Health Study). Am J Cardiol. 2013;111(3):418-24.

[6]Grey A, Mitnick MA, Shapses S, et al. Circulating levels of interleukin-6 and tumor necrosis factor-alpha are elevated in primary hyperparathyroidism and correlate with markers of bone resorption--a clinical research center study. J Clin Endocrinol Metab. 1996;81(10):3450-54.

[7]Emam AA, Mousa SG, Ahmed KY, et al. Inflammatory biomarkers in patients with asymptomatic primary hyperparathyroidism. Med Princ Pract. 2012;21(3):249-53.

[8]Rashid G, Bernheim J, Green J, et al. Parathyroid hormone stimulates endothelial expression of atherosclerotic parameters through protein kinase pathways. Am J Physiol Renal Physiol. 2007;292(4):121518.

[9]Bonet J, Bayés B, Fernández-Crespo P, et al. Cinacalcet may reduce arterial stiffness in patients with chronic renal disease and secondary hyperparathyroidism - results of a small-scale, prospective, observational study. Clin Nephrol. 2011;75(3):181-87.

[10]Pitchford SC, Momi S, Giannini S, et al. Platelet P-selectin is required for pulmonary eosinophil and lymphocyte recruitment in a 
murine model of allergic inflammation. Blood. 2005;105(5):2074-81.

[11] Grove EL, Hvas AM, Kristensen SD. Immature platelets in patients with acute coronary syndromes. Thromb Haemost. 2009;101(1):151-56.

[12]Ranjith MP, Divya R, Mehta VK, et al. Significance of platelet volume indices and platelet count in ischaemic heart disease. $\mathbf{J}$ Clin Pathol. 2009;62(9):830-33.

[13]Henn V, Slupsky JR, Grafe M, et al. CD40 ligand on activated platelets triggers an inflammatory reaction of endothelial cells. Nature. 1998;391(6667): 591-4.

[14] Aktas G, Sit M, Tekce H, et al. Mean platelet volume in nasal polyps. West Indian Med J. 2013;62(6):515-18.

[15] van der Loo B, Martin JF. Megakaryocytes and platelets in vascular disease. Baillieres Clin Haematol. 1997;10(1):109-23.

[16] Kiliçli-Camur N, Demirtunç R, Konuralp C, et al. Could mean platelet volume be a predictive marker for acute myocardial infarction? Med Sci Monit. 2005;11(8):38792.

[17] Kapsoritakis AN, Koukourakis MI, Sfiridaki A, et al. Mean platelet volume: a useful marker of inflammatory bowel disease activity. Am J Gastroenterol. 2001;96(3):776-81.

[18] Kisacik B, Tufan A, Kalyoncu U, et al. Mean platelet volume (MPV) as an inflammatory marker in ankylosing spondylitis and rheumatoid arthritis. Joint Bone Spine. 2008;75(3):291-94.

[19] Choi CU, Seo HS, Kim YK, et al. Can mean platelet volume predict coronary vasospasm? Platelets. 2011;22(3):173-78.

[20]Endler G, Klimesch A, Sunder-Plassmann $\mathrm{H}$, et al. Mean platelet volume is an independent risk factor for myocardial infarction but not for coronary artery disease. Br J Haematol. 2002;117(2): 399404.

[21] Aktas G, Kocak MZ, Duman TT, et al. Mean Platelet Volume (MPV) as an inflammatory marker in type 2 diabetes mellitus and obesity. Bali Med J. 2018;7(3):650-53.

[22]Bilgin S, Aktas G, Kahveci G, et al. Does mean platelet volume/lymphocyte count ratio associate with frailty in type 2 diabetes mellitus? Bratisl Med J. 2021;122(2):11619.

[23] Aktas G. Hematological predictors of novel coronavirus infection. Rev Assoc Med Bras. 2021;67(1):1-2.

[24] Sincer I, Gunes Y, Mansiroglu AK, et al. Association of mean platelet volume and red blood cell distribution width with coronary collateral development in stable coronary artery disease. Adv Interv Cardiol. 2018;14(3):263-69.

[25] Sen BB, Rifaioglu EN, Ekiz O, et al. Neutrophil to lymphocyte ratio as a measure of systemic inflammation in psoriasis. Cutan Ocul Toxicol. 2014;33(3):223-27.

[26] Kaya H, Ertas F, Islamoglu Y, et al. Association between neutrophil to lymphocyte ratio and severity of coronary artery disease. Clin Appl Thromb Hemost. 2013;20(1):50-4

[27] Templeton AJ, McNamara MG, Šeruga B, et al. Prognostic role of neutrophil-tolymphocyte ratio in solid tumors: a systematic review and meta-analysis. J Natl Cancer Inst. 2014;106(6):124.

[28]Liu X, Shen Y, Wang H, et al. Prognostic Significance of Neutrophil-to-Lymphocyte Ratio in Patients with Sepsis: A Prospective Observational Study. Mediators Inflamm. 2016;2016:8191254.

[29]Baldane S, Ipekci SH, Sozen M, et al. Mean platelet volume could be a possible biomarker for papillary thyroid carcinomas. 
Asian Pac J Cancer Prev. 2015;16(7):267174.

[30] Butterworth RJ, Bath PM. The relationship between mean platelet volume, stroke subtype and clinical outcome. Platelets. 1998;9(6):359-64.

[31]Kuzu F, Arpaci D, Cakmak GK, et al. The value of blood cell markers in patients with thyroid nodules including atypia of undetermined significance/follicular lesion of undetermined significance cytology. Medicine. 2018;7(2):386-90.

[32] Carlioglu A, Timur O, Durmaz SA. Mean platelet volume in euthyroid patients with Hashimoto's thyroiditis. Blood Coagulation \& Fibrinolysis. 2015;26(3):282-84.

[33] Atılgan CU, Şendül SY, Kösekahya P, et al. Evaluation of Neutrophil-to-Lymphocyte Ratio and Mean Platelet Volume in Patients with Active and Inactive Thyroid Orbitopathy. Sisli Etfal Hastan Tip Bul. 2018;52(1):26-30.

[34]Erem C, Kocak M, Hacihasanoglu A, et al. Blood coagulation, fibrinolysis and lipid profile in patients with primary hyperparathyroidism: increased plasma factor VII and X activities and D-Dimer levels. Exp Clin Endocrinol Diabetes. 2008;116(10):619-24.

[35] Yorulmaz G, Akalın A, Akay OM, et al. The Effect of Hyperparathyroid State on Platelet Functions and Bone Loss. Turk J Haematol. 2016;33(4):293-98.

[36] Arpaci D, Kuzu F, Emre AU, et al. Elevated mean platelet volume in patients with primary hyperparathyroidism. Int J Clin Exp Med. 2016;9(3):6330-35.

[37] Yilmaz H. Assessment of mean platelet volume (MPV) in primary hyperparathyroidism: effects of successful parathyroidectomy on MPV levels. Endocr Regul. 2014;48(4):182-88.
[38]Baradaran A, Nasri H. Impact of parathormone Hormone on Platelet Count and Mean Volume in End-stage Renal Failure Patients on regular Hemodialysis. J Med Sci. 2005;5(4): 266-71.

[39]Fliser D, Franek E, Fode P, et al. Subacute infusion of physiological doses of parathyroid hormone raises blood pressure in humans. Nephrol Dial Transplant. 1997;12(5):933-38.

[40] Salzman EW, Ware JA. Ionized calcium as an intracellular messenger in blood platelets. Prog Hemost Thromb.1989;9:177-202.

[41]Rashid G, Bernheim J, Green J, et al. Benchetrit S. Parathyroid hormone stimulates the endothelial nitric oxide synthase through protein kinase $\mathrm{A}$ and $\mathrm{C}$ pathways. Nephrol Dial Transplant. 2007;22(10):2831-37.

[42] Cure CM, Cure E, Yuce S, et al. Mean platelet volume and vitamin D level. Ann Lab Med. 2014;34(2):98-103.

[43] Walker MD, Fleischer J, Rundek T, et al. Carotid vascular abnormalities in primary hyperparathyroidism. J Clin Endocrinol Metab. 2009;94(10):3849-56.

[44] Christensen MH, Fenne IS, Nordbo Y, et al. Novel inflammatory biomarkers in primary hyperparathyroidism. Eur J Endocrinol. 2015;173(1):9-17.

[45] Shen XH, Chen Q, Shi Y, et al. Association of neutrophil/ lymphocyte ratio with longterm mortality after ST elevation myocardial infarction treated with primary percutaneous coronary intervention. Chin Med J. 2010;123(23):3438-43.

[46]Lam H, Yang P, Chien M, et al. Association between neutrophil-to-lymphocyte ratio and parathyroid hormone in patients with primary hyperparathyroidism. Archives of Medical Science. 2019;15(4):880-86. 
[47]Zeren S, Yaylak F, Ozbay I, et al. Relationship between the neutrophil to lymphocyte ratio and parathyroid adenoma size in patients with primary hyperparathyroidism. Int Surg. 2015;100(78):1185-89.

[48] Toraman A, Aras F, Hekimsoy Z, et al. Is there a relationship between parathyroid hormone and neutrophil lymphocyte ratio or platelet lymphocyte ratio? Acta Endocrinol (Buchar). 2019;5(1):96-101. 